\title{
Relação entre a patogenicidade do Schistoma mansoni em camundongos e a susceptibilidade do molusco vetor. II. Número de ovos nas fezes e número e tamanho dos granulomas nas visceras*
}

\author{
Relationship between the pathogenicity of Schistoma mansoni in mice and the \\ susceptibility of the vector mollusc. Il. Number of eggs in the feces and number \\ and size of granulomas in the visceras
}

\author{
Eliana Maria Zanotti-Magalhães **, Luiz Augusto Magalhães **, José Ferreira de Carvalho ***
}

\begin{abstract}
ZANOTTI-MAGALHÃES, E.M. et al. Relação entre a patogenicidade do Schistoma mansoni em camundongos $\mathrm{e}$ a susceptibilidade do molusco vetor. II. Número de ovos nas fezes e número e tamanho dos granulomas nas vísceras. Rev. Saúde Pública, 27: 412-20, 1993. Estudou-se a influência da susceptibilidade de moluscos vetores do $S$. mansoni no desenvolvimento da patogenicidade do trematódeo no hospedeiro definitivo. Foram utilizadas progênies de moluscos Biomphalaria tenagophila e Biomphalaria glabrata selecionadas para o caráter susceptibilidade ao $S$. mansoni das linhagens $\mathrm{SJ}$ e $\mathrm{BH}$, respectivamente. Cercárias oriundas das gerações $\mathrm{P}, \mathrm{F}_{1}, \mathrm{~F}_{2}, \mathrm{~F}_{3}$ c $F_{4}$ foram usadas para a infecção de camundongos $S$ wiss, que foram sacrificados oito semanas após a exposição às larvas. Por csta ocasião verificou-se o número de ovos nas fezes e o número de granulomas no fígado, baço e intestino. Avaliou-se também o tamanho das reações granulomatosas nestas vísceras. Concluiu-se que a maior susceptibilidade de $B$. tenagophila induziu a uma maior eliminação de ovos do parasita nas fezes. Verificou-se maior número de granulomas por área de tecido hepático em roedores infectados com cercárias oriundas de moluscos mais susceptívcis. Nos mesmos rocdores, constatou-se relação inversa entre a área dos granulomas esplênicos, hepáticos e intestinais e a taxa de infecção dos moluscos que forneceram as cercárias para a infecção dos camundongos.
\end{abstract}

Descritores: Schistosoma mansoni, patogenicidade. Biomphalaria, parasitologia. Contagem de ovos de parasitas, utilidade. Granuloma. Parasitologia.

\section{Introdução}

Paraense \& Correa ${ }^{25,26,27}(1963,1978)$, estudando populaçõcs de Biomphalaria slabrata c Biomphalaria tenagophila expostas ao S. mansoni de várias localidades, verificaram diferentes graus de susceptibilidade cntre as populações c o

* Realizado com o auxílio financeiro da Financiadora de Estudos e Projetos (FNTEP) - Processo $n^{9} 43.81 .0417 .0$ e do Conselho Nacional de Desenvolvimento Científico e Tecnológico (CNPq) - Processo $n^{\circledR} 40.0798 .85$ ).

* Departamento de Parasitologia do Instituto de Biologia da Universidade Estadual de Campinas - Campinas, SP - Brasil

*** Departamento de Estatística do Instituto de Matemática, Estatística e Ciências da Computação da Universidade Estadual de Campinas - Campinas, SP - Brasil

Scparata/Reprints: E.M. Zanotti-Magalhães - Caixa Postal 6109 - Cidade Universitária - Barão Geraldo - 13083-970 - Campinas, SP - Brasil

Edição subvencionada pela FAPESP. Processo Medicina 93/ $0208-5$. parasita. Esses autores descreveram $\mathrm{cm} 1963^{26}$ a existência no Brasil de duas linhagens do trematódeo: a linhagem SJ, oriunda do Vale do Rio Paraíba (SP) e mantida $\mathrm{cm}$ populações locais de $B$. tenagophila; c a linhagem $\mathrm{BH}$, originada em Bclo Horizonte $(\mathrm{BH})$ c mantida em populações simpátricas de $B$. glabrata. Ambas as espécies de moluscos mostraram-se refratárias à infecção pelo $S$. mansoni alopátrico, sugcrindo adaptação fisiológica entre o molusco e a linhagem local do parasita.

A susceptibilidade à infecção pelo S. mansoni é um caráter genético e hereditário apresentado por B. glabrata c B. tenagophila (Newton ${ }^{24}, 1053$; Richards $^{30,32}$, 1970, 1977; Richards \& Merritt ${ }^{31}$, 1972; Santana c col. ${ }^{34}, 1978$ ).

A resistência dos moluscos à infecção pelo $S$. mansoni manifesta-se pela intensa rcação amebocitária $\mathrm{em}$ torno dos esporocistos, levando-os à morte, enquanto que em moluscos susceptívcis, a reação ć branda e os esporocistos permanecem em sua maioria viáveis $\left(\right.$ Newton $^{23}, 1952$; Coelho ${ }^{9}$, 1962; Guaraldo c col. ${ }^{14}$, 1981). 
Se a relação entre o caramujo e o parasita $\varepsilon$ aspecto de interesse para a epidemiologia da esquistossomose, é de interesse também, a relação do parasita com seu hospedeiro definitivo, principalmente se forem considerados os elementos que determinam a patogenicidade do parasita e seu modo de propagação. No caso da esquistossomose mansônica, ao ovo do parasita é atribuído o principal papel patogênico além de ser responsável pela disseminação da espécie.

Em torno dos ovos de $S$. mansoni, não eliminados com as fezes do hospedeiro vertebrado, há formação de intensa reação inflamatória (granuloma) de caráter imune.

Magalhães e col. ${ }^{21}$ (1975), estudando as linhagens $\mathrm{BH}$ e SJ do $S$. mansoni em camundongos, verificaram maior número de granulomas hepáticos por verme na linhagem BH, se comparada com a linhagem SJ. Nas áreas endêmicas dominadas pela linhagem $\mathrm{BH}$ observam-se indivíduos com esquistossomose hepatosplênica descompensada, enquanto que, nas áreas abrangidas pela linhagem SJ, o quadro clínico na quase totalidade dos casos, é assintomático (Dias c col. ${ }^{11}, 1988$ ), sendo raros os casos de hepatosplenomegalia compensada (Santos ${ }^{33}, 1967 ;$ Lima $^{19}, 1991$ ). Apesar da baixa infectividade apresentada por $B$. tenagophila, csta espécic tcm sido responsável pela manutenção c expansão da esquistossomosc mansônica para o sul do Brasil.

$O$ objetivo do presente trabalho foi verificar a relação entre a maior facilidade com que o parasita se desenvolve no molusco $\mathrm{c}$ o grau de patogenicidade apresentado pelo trematódeo no hospedciro definitivo. Nesta segunda fase de apresentação dos resultados abordou-se a susceptibilidade de $B$. glabrata $\mathrm{e} B$. tenagophila $\mathrm{c}$ o número $\mathrm{c}$ tamanho dos granulomas nas vísceras $\mathrm{c}$ o númcro de ovos eliminados com as fezes dos camundongos.

\section{Material e Método}

\section{Animais Utilizados}

\section{a) Moluscos vetores}

Moluscos com diferentes graus de susceptibilidade foram obtidos por autofecundação dos moluscos susceptíveis. Foram utilizados cspécimes de $B$. glabrata e $B$. lenagophila cxpostos, respectivamente, às linhagens $\mathrm{BH}$ c SJ.

Foram obtidas cinco progênies de $B$. glabrata $\left(\mathrm{P}, \mathrm{F}_{1}, \mathrm{~F}_{2}, \mathrm{~F}_{3}\right.$ e $\left.\mathrm{F}_{4}\right)$ e de $B$. tenagophila $\left(\mathrm{P}, \mathrm{F}_{1}, \mathrm{~F}_{2}, \mathrm{~F}_{3}\right.$ e $\mathrm{F}_{4}$ ), que foram expostas a dez miracídios de $S$. mansoni. As cercárias eliminadas pclos moluscos foram utilizadas na infecção de camundongos.
Os planorbídeos foram observados por seis meses para a determinação da susceptibilidade.

Maiores detalhes sobre a seleção dos moluscos e obtenção das cercárias podem ser obtidos no trabalho anterior (Zanotti-Magalhães e col. ${ }^{37}$, 1991).

\section{b) Hospedeiros definitivos}

Camundongos Swiss, SPF, albinos, provenientes do Biotério Central da UNICAMP, foram usados como hospedeiros definitivos.

Cercárias oriundas das geraçð̌es $\mathrm{P}, \mathrm{F}_{1}, \mathrm{~F}_{2}, \mathrm{~F}_{3} \mathrm{e}$ $\mathrm{F}_{4}$ de $B$. glabrata e $B$. tenagophila, respectivamente, foram utilizadas para infecção dos camundongos.

A especificação completa dos grupos formados foi a seguinte:

\section{Camundongos infectados com a linhagem BH:}

- 20 camundongos infectados com cercárias da gcração parental (BHP).

- 19 camundongos infectados com cercárias da gcração $F_{1}\left(B H F_{1}\right)$.

- 20 camundongos infectados com cercárias da geração $\mathrm{F}_{2}\left(\mathrm{BHF}_{2}\right)$.

- 27 camundongos infectados com cercárias da gcração $\mathrm{F}_{3}\left(\mathrm{BHF}_{3}\right)$.

- 25 camundongos infectados com cercárias da geração $\mathrm{F}_{4}\left(\mathrm{BHF}_{4}\right)$.

\section{Camundongos infectados com a linhagem SJ}

- 14 camundongos infectados com cercárias da geração parental (SJP).

- 18 camundongos infectados com cercárias da geração $\mathrm{F}_{1}\left(\mathrm{SJF}_{1}\right)$.

- 19 camundongos infectados com cercárias da gcração $\mathrm{F}_{2}\left(\mathrm{SJF}_{2}\right)$.

- 18 camundongos infectados com cercárias da gcração $\mathrm{F}_{3}\left(\mathrm{SJF}_{3}\right)$.

- 10 camundongos infectados com ccrcárias da geração $\mathrm{F}_{4}\left(\mathrm{SJF}_{4}\right)$.

Os subgrupos de camundongos foram constituídos à madida que as ccrcárias foram sendo eliminadas pelos caramujos.

\section{Infecção dos Camundongos}

Cercárias foram obtidas após a exposição dos moluscos infectados, à luz e ao calor de $28^{\circ} \mathrm{C}$.

Os camundongos foram infectados percutaneamente, pcla cauda, por cem ccrcárias, seguindo técnica de Magalhães 20 (1969).

Após oito semanas de infecção, os roedores sobreviventes foram sacrificados por deslocamento 
cervical, realizando-se a perfusão do sistema porta hepático (Yolles e col. ${ }^{36}, 1947$ ).

\section{Obtenção e Contagem de Granulomas Hepáticos}

Posteriormente à perfusão, o fígado dos animais foi homogeneizado em liquidificador, para determinação do número de granulomas totais, segundo técnica de Pellegrino \& Brener ${ }^{28}$ (1956).

Além disso, um fragmento da víscera foi fixado em Bouin, a fim de se determinar o número de reações granulomatosas por área de corte histológico de $7 \mu \mathrm{m}$ de espessura.

Os granulomas foram observados em microscópio óptico comum. A determinação da área tissular foi realizada de acordo com Magalhães e col. $^{22}$ (1979).

\section{Obtenção e Contagem de Granulomas Esplênicos e Instestinais}

Fragmentos do baço e do colo ascendente foram fixados em Bouin. Cortes histológicos de 7 $\mu \mathrm{m}$ de espessura foram utilizados para a obscrvação de granulomas.

A área de tecido cxaminado foi determinada conforme especificado no ítem anterior para o rigado.

\section{Verificação do Tamanho da Reação Granulomatosa}

O tamanho da rcação granulomatosa $\mathrm{cm}$ torno do ovo de $S$. mansoni foi medida para avaliação da atividade celular apresentada pelos rocdores infectados.

Através de cortes histológicos e com o auxílio de ocular micrométrica Zeiss, foram medidos os diâmetros maior e menor dos granulomas. Para uma mclhor delimitação da reação granulomatosa, os cortcs histológicos foram corados com tricrômico de Gomori. Foram medidos todos os granulomas presentes $\mathrm{cm}$ um corte histológico. Somente foram medidos os granulomas que aprescntavam $\mathrm{em}$ seu núclco um ovo de $S$. mansoni, que comprovava a condição de que o corte estava próximo de seu diâmetro máximo.

Para a análise estatística considerou-se a área dos granulomas presentes no baço, fígado e intestino.

\section{Verificação do Número de Ovos de S. mansoni Eliminados nas Fezes.}

Por ocasião da necrópsia, as fezes dos rocdores contidas no reto foram colctadas.

O númcro de ovos presentes na maléria fecal foi vcrificado pelo método de Kato (Komyia \& Kobayashi $\left.{ }^{16}, 1966\right)$.

\section{Métodos de Análise Estatística}

Os camundongos foram aleatoriamente distribuídos pclos 10 grupos descritos, constituindo experimento completamente aleatorizado. Os resultados foram submetidos à análise estatística, baseada nesse esquema experimental. Foram feitas comparações entre os grupos através de procedimentos usuais de análise de variância. Procedeu-se, também, ao estudo dos efeitos de linhagem e de taxa de infecção dos moluscos em cada resposta. A taxa de infecção dos moluscos dá um índice de susceptibilidade, cujo modelo adotado pode ser escrito:

$$
\mathrm{y}_{\mathrm{ij}}+\mathrm{u}+\mathrm{L}_{\mathrm{i}}+\mathrm{O}_{\mathrm{i}} \mathrm{T}_{\mathrm{ij}}+\mathrm{c}_{\mathrm{ij}} \text {, }
$$

onde $L$ representa o efeito de linhagem, $T$ a taxa de infecção relativa ao animal j na linhagem i e $O$ o cfeito da taxa na resposta. $O$ termo $e$ corresponde ao crro experimental. Note-se que este modelo corresponde ao ajuste de uma reta para cada linhagem. O modelo foi vcrificado através de extensa análise de resíduos e considerado adequado. Com a análisc, é possível identificar-sc os efcitos (ou diferenças) de linhagens e os devidos à taxa de infecção. Os cálculos foram feitos com o software SAS ${ }^{\mathrm{R}}$, em computador compativel com IBM-PC.

\section{Resultados}

Os resultados referentes à susceptibilidade das gcrações $\mathrm{P}, \mathrm{F}_{1}, \mathrm{~F}_{2}, \mathrm{~F}_{3}, \mathrm{c} \mathrm{F}_{4}$ de $B$. glabrata e $B$. tenagophila, expostas à infecção pelas respectivas geraçōes de $S$. mansoni, estão apresentados na Tabcla 1. Até a geração $F_{3}$, obscrvou-sc um accntuado aumento da taxa de infecção dos moluscos dc ambas espécics.

Tabela 1. Taxa de infecção das gerações de B. glabrata e B. tenagophila submetidas à infecção pelas correspondentes gerações de $S$. mansoni, respectivamente das linhagens $\mathrm{BH}$ e SJ.

\begin{tabular}{|c|c|c|c|c|}
\hline Espécie & $\begin{array}{l}\text { Geração } \\
\text { dos molus- } \\
\text { cos e do } \\
\text { S. mansoni }\end{array}$ & $\begin{array}{l}\mathrm{N}^{e} \text { de } \\
\text { moluscos } \\
\text { exami- } \\
\text { nados }\end{array}$ & $\begin{array}{l}\text { No de mo- } \\
\text { luscos que } \\
\text { eliminaram } \\
\text { cercárias }\end{array}$ & $\begin{array}{c}\text { Taxa de } \\
\text { infecção } \\
(\%)\end{array}$ \\
\hline B. glabrata & $\begin{array}{l}P \\
F_{1} \\
F_{2} \\
F_{3} \\
F_{4}\end{array}$ & $\begin{array}{l}50 \\
29 \\
66 \\
19 \\
20 \\
\end{array}$ & $\begin{array}{l}22 \\
20 \\
48 \\
14 \\
12 \\
\end{array}$ & $\begin{array}{l}44 \\
69 \\
73 \\
74 \\
60 \\
\end{array}$ \\
\hline $\begin{array}{l}\text { B. tenago- } \\
\text { phila }\end{array}$ & $\begin{array}{l}P \\
F_{1} \\
F_{2} \\
F_{3} \\
F_{4}\end{array}$ & $\begin{array}{l}59 \\
72 \\
47 \\
52 \\
27\end{array}$ & $\begin{array}{r}9 \\
35 \\
28 \\
35 \\
7\end{array}$ & $\begin{array}{l}15 \\
49 \\
60 \\
67 \\
26\end{array}$ \\
\hline
\end{tabular}


$\mathrm{Na}$ Tabela 2 podem ser observados os resultados referentes ao número de ovos de $S$. mansoni presentes nas fezes dos camundongos, assim como o número de reações granulomatosas verificadas no baço e no intestino. $\mathrm{Na}$ Tabela 5 , a análise de variância evidencia o efeito da taxa de infecção dos moluscos e da linhagem do trematódeo sobre o númcro de ovos e o númcro de granulomas no baço e no intestino. As Figuras 1, 2 e 3 mostram de maneira mais dircta o efeito quantitativo. Considerando o número de ovos nas fezes dos roedores, verificou-se comportamento diferente para as linhagens BH e SJ. Para a linhagem SJ verificou-se um aumento no númcro de ovos com a maior susceptibilidade de $B$. tenagophila, enquanto que a maior susceptibilidade de $B$. glabrata resultou em menor eliminação de ovos pelas fezes.

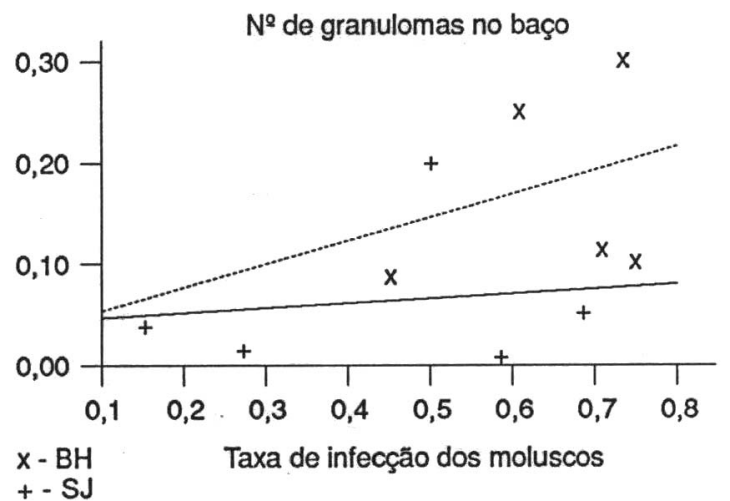

Figura 2. Número de reaçőes granulomatosas por área de tecido esplênico nas infecçoes por $S$. mansoni das linhagens BH e SJ em funçăo das taxas de infecçăo de B. glabrata $\Theta B$. tenagophila.

Tabela 2. Número médio de ovos de $S$. mansoni eliminados nas fezes e número médio de granulomas por área de tecido esplênico e intestinal em camundongos infectados com as linhagens $\mathrm{BH}$ e $\mathrm{SJ}$ do tramatódeo.

\begin{tabular}{lcccc}
\hline Linhagem & Geração & No de ovos/g de fezes & \multicolumn{2}{c}{$N^{2}$ de granulomas/mm² de área de tecido } \\
\cline { 3 - 5 } & & & Baço & Intestino \\
\hline BH & $P$ & $2949,50 \pm 2669,33$ & $0,10 \pm 0,12$ & $0,86 \pm 0,64$ \\
& $F_{1}$ & $2322,04 \pm 2024,30$ & $0,11 \pm 0,20$ & $1,10 \pm 0,78$ \\
& $F_{2}$ & $1509,52 \pm 1385,96$ & $0,31 \pm 0,31$ & $1,87 \pm 1,67$ \\
& $F_{3}$ & $1801,60 \pm 1253,62$ & $0,11 \pm 0,26$ & $1,18 \pm 0,77$ \\
& $F_{4}$ & $1699,65 \pm 1802,05$ & $0,26 \pm 0,39$ & $2,16 \pm 1,23$ \\
\hline SJ & $P$ & $1750,48 \pm 1408,83$ & $0,04 \pm 0,08$ & $0,75 \pm 0,57$ \\
& $F_{1}$ & $3029,25 \pm 1522,88$ & $0,20 \pm 0,34$ & $1,01 \pm 0,59$ \\
& $F_{2}$ & $3875,55 \pm 3172,76$ & $0,01 \pm 0,02$ & $0,85 \pm 1,45$ \\
& $F_{3}$ & $3836,22 \pm 3794,38$ & $0,06 \pm 0,06$ & $0,91 \pm 1,07$ \\
& $F_{4}$ & $487,99 \pm 449,12$ & $0,01 \pm 0,01$ & $0,34 \pm 0,22$ \\
\hline
\end{tabular}

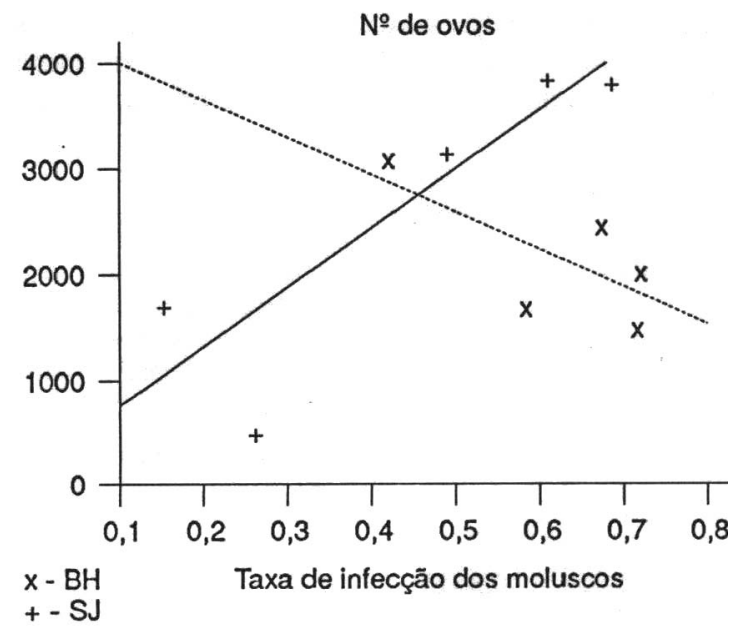

Figura 1. Número de ovos de Schistosoma masoni das linhagens $\mathrm{BH}$ e $\mathrm{SJ}$ eliminados nas fezes em função das taxas de infecçāo apresentadas por $B$. glabrata e $B$. tenagophila.
Tabela 3. Número médio de granulomas no figado de camundongos infectados pelas linhagens $\mathrm{BH}$ e SJ de $S$. mansoni.

\begin{tabular}{cccc}
\hline Linhagem Geração & \multicolumn{2}{c}{$N^{2}$ de granulomas hepáticos } \\
\cline { 3 - 4 } & & $\begin{array}{c}N^{2} \text { de } \\
\text { granulomas } \\
\text { totais* }\end{array}$ & $\begin{array}{c}N^{2} \text { de } \\
\text { granulomas/mm } \\
\text { de corte } \\
\text { histológico }\end{array}$ \\
\hline $\mathrm{BH}$ & $\mathrm{P}$ & $5853,79 \pm 2051,26$ & $1,60 \pm 0,46$ \\
& $\mathrm{~F}_{1}$ & $7293,70 \pm 3517,02$ & $1,82 \pm 0,65$ \\
& $\mathrm{~F}_{2}$ & $5444,45 \pm 1403,73$ & $3,19 \pm 2,87$ \\
& $\mathrm{~F}_{3}$ & $5895,52 \pm 1941,47$ & $2,27 \pm 0,84$ \\
& $\mathrm{~F}_{4}$ & $7977,64 \pm 3033,14$ & $2,43 \pm 0,47$ \\
\hline $\mathrm{SJ}$ & $\mathrm{P}$ & $3692,64 \pm 1151,23$ & $1,08 \pm 0,41$ \\
& $\mathrm{~F}_{1}$ & $6583,01 \pm 1871,36$ & $2,29 \pm 0,51$ \\
& $\mathrm{~F}_{2}$ & $4227,15 \pm 1518,47$ & $1,88 \pm 0,78$ \\
& $\mathrm{~F}_{3}$ & $4952,83 \pm 1580,55$ & $2,30 \pm 0,82$ \\
& $\mathrm{~F}_{4}$ & $3705,05 \pm 1301,56$ & $1,62 \pm 0,62$ \\
\hline
\end{tabular}

- Número de granulomas detrminado após a liquidação do figado. 


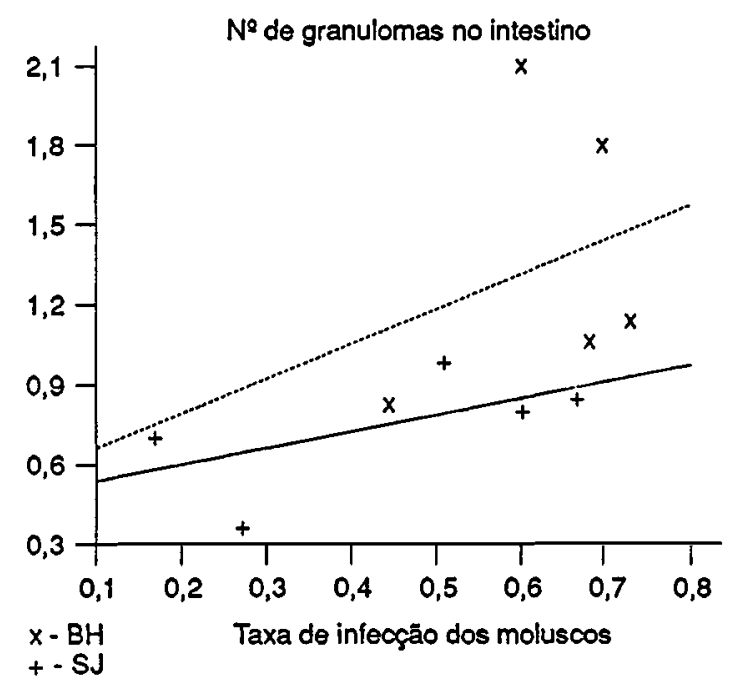

Figura 3. Número de reações granulomatosas por área de tecido intestinal nas infecçðes por $S$. mansoni das linhagens $\mathrm{BH}$ e SJ em função das taxas de infecção apresentadas por B. glabrata $\in$ B. tenagophila.

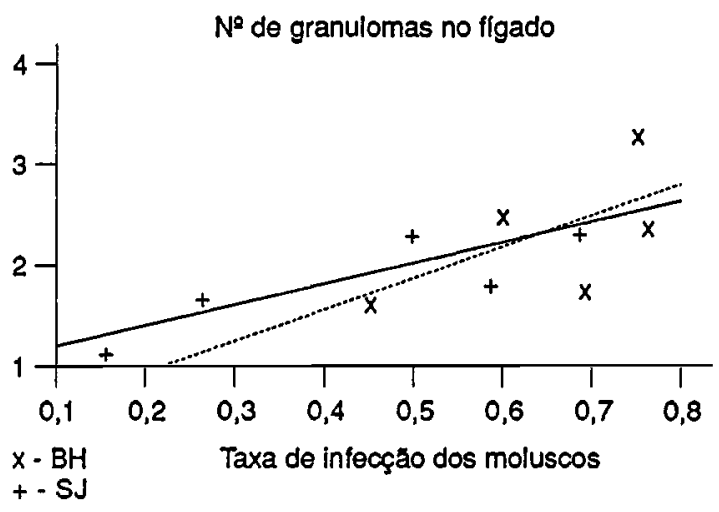

Figura 4. Número de reaçరes granulomatosas por área de tecido hepático nas infeccóes por $S$. mansoni das linhagens $\mathrm{BH} \theta \mathrm{SJ}$ em funçăo das taxas de infecçăo apresentadas por B. glabrata e B. tenagophila.
Tabela 4. Diâmetro médio dos granulomas observados no baço, figado e intestino dos camundongos infectados com as linhagens $\mathrm{BH}$ e SJ de S. mansoni.

\begin{tabular}{lcccc}
\hline Linhagem Geração & \multicolumn{3}{c}{$\begin{array}{c}\text { Diâmetro médio dos } \\
\text { granulomas (mm) }\end{array}$} \\
\cline { 3 - 6 } & & Baço & Figado & Intestino \\
\hline BH & P & $0,26 \pm 0,05$ & $0,36 \pm 0,09$ & $0,24 \pm 0,05$ \\
& $F_{1}$ & $0,24 \pm 0,08$ & $0,32 \pm 0,10$ & $0,25 \pm 0,06$ \\
& $F_{2}$ & $0,20 \pm 0,04$ & $0,24 \pm 0,06$ & $0,13 \pm 0,04$ \\
& $F_{3}$ & $0,22 \pm 0,05$ & $0,25 \pm 0,06$ & $0,20 \pm 0,02$ \\
& $F_{4}$ & $0,24 \pm 0,05$ & $0,30 \pm 0,08$ & $0,22 \pm 0,05$ \\
\hline SJ & $P_{y y y}$ & $0,31 \pm 0,09$ & $0,31 \pm 0,07$ & $0,22 \pm 0,05$ \\
& $F_{1}$ & $0,24 \pm 0,05$ & $0,31 \pm 0,07$ & $0,22 \pm 0,05$ \\
& $F_{2}$ & $0,17^{\star}$ & $0,26 \pm 0,07$ & $0,18 \pm 0,04$ \\
& $F_{3}$ & $0,24 \pm 0,05$ & $0,26 \pm 0,08$ & $0,24 \pm 0,07$ \\
& $F_{4}$ & $0,30 \pm 0,03$ & $0,28 \pm 0,06$ & $0,20 \pm 0,06$ \\
& & &
\end{tabular}

- Medida de um único granuloma.

O número de granulomas por área de tecido esplênico ou intestinal não diferiu significativamente entre as linhagens e com relação ao aumento das taxas de infecção dos moluscos.

Nas Tabelas 3 e 6 estão apresentados os resultados relativos ao número de granulomas presentes no figado, obtido através da liquidificação do órgão (granuloma total) e da determinação por área de corte histológico. Através da análise de variância evidenciou-se aumento no número de reaçōes granulomatosas, por área hepática, em consequiência da maior susceptibilidade de $B$. glabrata $e B$. tenagophila. A Figura 4 permite avaliar melhor este rcsultado. A liquidificação do fígado indicou diferença significativa no número de lesões no órgão cntre as linhagens BH e SJ ( Tabela 6).

Nas Tabelas 4 e 7 e Figuras 5 e 6 estão apresentados os resultados concernentes ao tamanho dos granulomas presentes no baço, fígado e intestino por ocasião da necrópsia dos camundongos. Nessas

Tabela 5. Análise de variância (soma dos quadrados do tipo III) por respostas.

\begin{tabular}{|c|c|c|c|c|c|c|}
\hline \multirow[b]{3}{*}{ Fonte de variação } & \multicolumn{2}{|c|}{$N^{2}$ de ovos nas fezes } & \multicolumn{4}{|c|}{$N^{2}$ de granulomas } \\
\hline & \multirow[b]{2}{*}{ Valor } & \multirow[b]{2}{*}{ Nivel P } & \multicolumn{2}{|c|}{ Baço } & \multicolumn{2}{|c|}{ Intestino } \\
\hline & & & Valor & Nivel $P$ & Valor & Nivel $P$ \\
\hline \multicolumn{7}{|l|}{ Linhagem } \\
\hline $\begin{array}{l}\text { Soma dos quadrados } \\
\text { Graus de liberdade }\end{array}$ & $\begin{array}{c}32.265 .274,5 \\
1\end{array}$ & 0,0084 & $\begin{array}{l}0,0002 \\
1\end{array}$ & 0,9519 & $\begin{array}{l}0,009 \\
1\end{array}$ & 0,9257 \\
\hline \multicolumn{7}{|l|}{ Taxa (linhagem) } \\
\hline $\begin{array}{l}\text { Soma dos quadrados } \\
\text { Graus de liberdade }\end{array}$ & $\begin{array}{c}73.793 .459,5 \\
2\end{array}$ & 0,0005 & $\begin{array}{l}0,0447 \\
2\end{array}$ & 0,6643 & $\begin{array}{l}2,7 \\
2\end{array}$ & 0,2595 \\
\hline \multicolumn{7}{|l|}{ Residuos } \\
\hline $\begin{array}{l}\text { Soma dos quadrados } \\
\text { Graus de liberdado }\end{array}$ & $\begin{array}{c}525.525 .449,8 \\
117\end{array}$ & & $\begin{array}{r}6,4 \\
117^{6}\end{array}$ & & $\begin{array}{l}114,6 \\
116\end{array}$ & \\
\hline
\end{tabular}


Tabela 6. Análise de variância (soma dos quadrados do tipo III) por respostas.

\begin{tabular}{|c|c|c|c|c|}
\hline \multirow[b]{2}{*}{ Fonte de variação } & \multicolumn{2}{|c|}{$\begin{array}{l}\text { Ne de granulomas } \\
\text { hepáticos totais }\end{array}$} & \multicolumn{2}{|c|}{$\begin{array}{c}N^{2} \text { de granulomas } / \mathrm{mm}^{2} \\
\text { de área hepática }\end{array}$} \\
\hline & Valor & NivelP & Valor & Nivel P \\
\hline $\begin{array}{l}\text { Linhagem } \\
\text { Soma dos quadrados } \\
\text { Graus de liberdade }\end{array}$ & $\begin{array}{c}15.016 .938,7 \\
1\end{array}$ & 0,0875 & $\begin{array}{l}0,5 \\
1\end{array}$ & 0,4876 \\
\hline $\begin{array}{l}\text { Taxa (linhagem) } \\
\text { Soma dos quadrados } \\
\text { Graus de liberdade }\end{array}$ & $\begin{array}{c}16.974 .258,7 \\
2\end{array}$ & 0,1912 & $\begin{array}{c}16,6 \\
2\end{array}$ & 0,0009 \\
\hline $\begin{array}{l}\text { Residuos } \\
\text { Soma dos quadrados } \\
\text { Graus de liberdade }\end{array}$ & $\begin{array}{c}591.815 .637,4 \\
117\end{array}$ & & $\begin{array}{l}129,2 \\
116\end{array}$ & \\
\hline
\end{tabular}

Tabela 7. Análise de variância (soma dos quadrados do tipo III) por respostas.

\begin{tabular}{|c|c|c|c|c|c|c|}
\hline \multirow[b]{3}{*}{ Fonte de variação } & \multicolumn{6}{|c|}{ Área dos granulomas } \\
\hline & \multicolumn{2}{|c|}{ Baço } & \multicolumn{2}{|c|}{ Figado } & \multicolumn{2}{|c|}{ Intestino } \\
\hline & Valor & Nivel $P$ & Valor & Nivel P & Valor & Nivel P \\
\hline \multicolumn{7}{|l|}{ Linhagem } \\
\hline $\begin{array}{l}\text { Soma dos quadrados } \\
\text { Graus de liberdade }\end{array}$ & $\begin{array}{l}0,0007 \\
1\end{array}$ & 0,3805 & $\begin{array}{l}0,0055 \\
1\end{array}$ & 0,0936 & $\begin{array}{l}0,00002 \\
1\end{array}$ & 0,8436 \\
\hline \multicolumn{7}{|l|}{ Taxa (linhagem) } \\
\hline $\begin{array}{l}\text { Soma dos quadrados } \\
\text { Graus de liberdade }\end{array}$ & $\begin{array}{l}0,0165 \\
8\end{array}$ & 0,0238 & $\begin{array}{l}0,0846 \\
8\end{array}$ & 0,0001 & $\begin{array}{l}0,0011 \\
8\end{array}$ & 0,0026 \\
\hline \multicolumn{7}{|l|}{ Residuos } \\
\hline $\begin{array}{l}\text { Soma dos quadrados } \\
\text { Graus de liberdade }\end{array}$ & $\begin{array}{l}0,0508 \\
60\end{array}$ & & ${ }_{162}^{0,3147}$ & & $\begin{array}{l}0,0261 \\
62\end{array}$ & \\
\hline
\end{tabular}

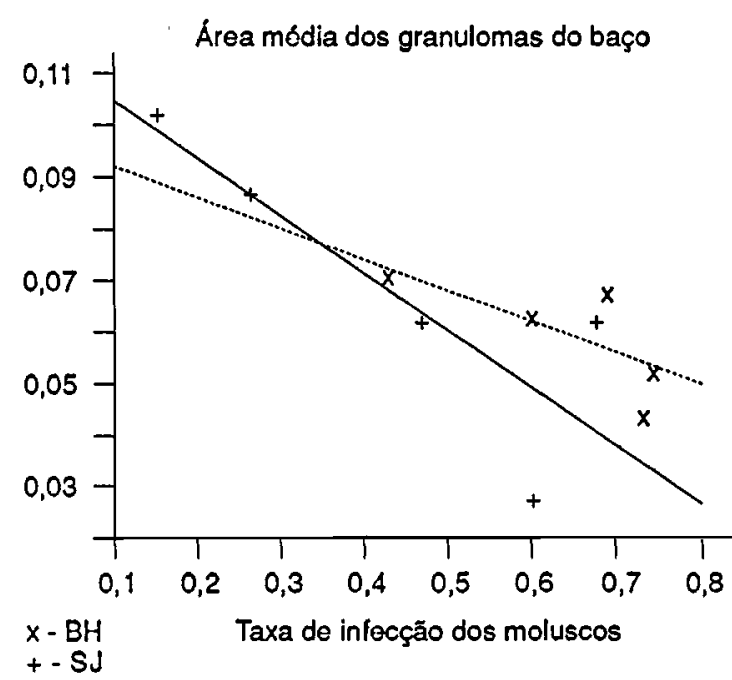

Figura 5. Area média dos granulomas do baço nas infecçōes por $S$. mansoni das linhagens $\mathrm{BH}$ e $\mathrm{SJ}$ em funçăo das taxas de infecção apresentadas por B. glabrata e B. tenagophila.

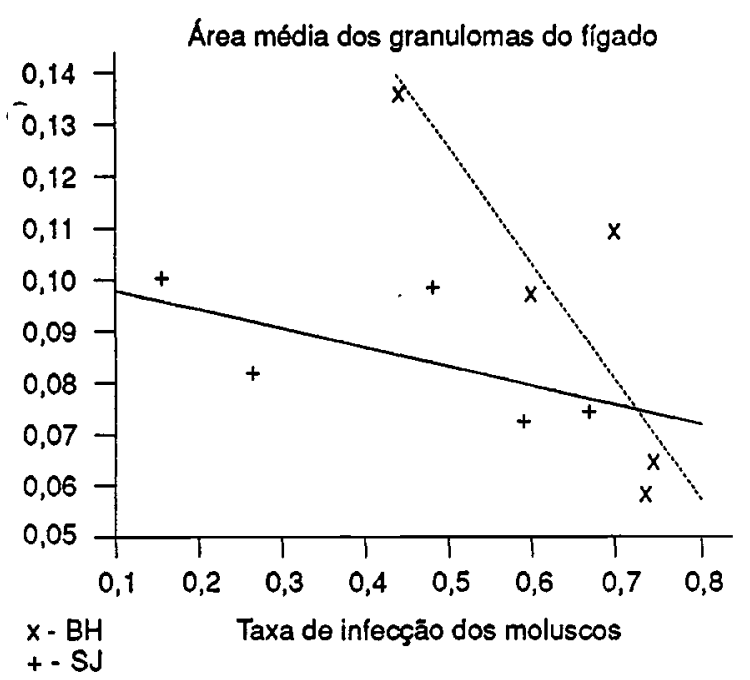

Figura 6. Área média dos granulomas do figado nas infecçōes por $S$. mansoni das linhagens $B H \in S J$ em funçăo das taxas de infeccão apresentadas por B. glabrata e B. tenagophila. 
três visceras observou-se significativa diminuição no tamanho das lesões granulomatosas decorrentes da maior susceptibilidade dos moluscos nos quais foram produzidas as respectivas cercárias.

\section{Discussão}

Conforme foi verificado por Cheever ${ }^{5}$ (1968) e Cheever e col. ${ }^{6}$ (1977), o número de ovos nas fezes, assim como nos tecidos humanos, cstá linearmente relacionado com o númcro de vermes fêmeos recuperados. No caso da esquistossomose mansônica no homem, parece haver uma relação entre a deposição de ovos nos tecidos, sua destruição pela reação granulomatosa e a eliminação de ovos pelas fezes do hospedeiro (Cheever e col. ${ }^{6}, 1977$ ). Sob este aspecto acreditamos ter confirmado as observaçōes acima referidas para a esquistossomose mansônica em camundongos, ao se verificar, na linhagem SJ, número crescente de vermes fêmeos e de ovos nas fezes dos roedores (ZanottiMagalhães e col. $\left.{ }^{37}, 1991\right)$. Na linhagem $\mathrm{BH}$, a maior susceptibilidade do moluscos se contrapôs a menor número de vermes fêmeos e, paralelamente, menor número de ovos foi verificado nas fezes dos camundongos.

Para vários autores, a principal diferença obscrvada cntrc os animais infectados com divcrsas linhagens de $S$. mansoni é a variação na densidade e distribuição dos ovos nos tccidos (Saoud ${ }^{35}, 1966$; Anderson \& Cheever ${ }^{1}, 1972$; Powers \& Checver $^{29}$, 1972; Kassim c col. ${ }^{15}$, 1979).

Apesar da afirmação de que a patogênese da csquistossomose mansônica ć principalmente determinada pela densidade dos ovos nos tccidos, Saoud ${ }^{35}$ (1966) não cvidenciou relação entre o númcro de ovos produzidos $\mathrm{c}$ a virulência do parasita, sugerindo que a ampla distribuição de ovos nos vários órgãos podcria estar mais relacionada com a maior virulência.

No presente experimento, o númcro de ovos climinados nas fezes difcriu entre as linhagens BH c SJ. A maior susceptibilidade de $B$. tenagophila implicou maior climinação de ovos pelas fezes dos camundongos. $\mathrm{O}$ número de ovos depositados nos tecidos hepático, esplênico c intestinal foi scmethante nas duas linhagens. A maior susceptibilidade de $B$. glabrata c $B$. tenagophila determinou maior deposição de ovos nos tecidos hepáticos.

Scgundo Docnhoff c col. ${ }^{12}$ (1986), cxistc uma significante correlação numérica entre o diâmetro dos granulomas hepáticos o númcro de ovos que são climinados com as fezes, sendo ambos cstes processos célula mediados. Numa fase mais adiantada da infecção esquistossomótica, obscrva-se redução ou modulação da reação granulomatosa, sendo que o processo de eliminação de ovos poderia, neste caso, ser controlado pela resposta imune humoral. Em animais imunocompetentes, podem ser formados, trombos inflamatórios, intravascularmente, em torno dos ovos, e esse fato poderia auxiliar a ruptura do endotélio vascular e permitir a penetração do ovo no tecido circunjacente.

A mediação celular, que modulou o granuloma no intestino dos roedores infectados pela linhagem SJ, não teria interferido na eliminação de ovos pelos camundongos parasitados por essa linhagem, observando-se maior eliminação de ovos com as fczes dos camundongos infectados por cercárias originadas de moluscos mais susceptiveis. Poderse-ia pensar, também, que uma discreta reação granulomatosa fosse insuficiente para reter os ovos na parede intestinal.

Com efeito, acredita-se que numa primeira fase os granulomas retêm os ovos ao nível da parede intestinal. Numa segunda etapa, o processo inflamatório intenso, a necrose e a destruição dos tecidos facilitariam a eliminação de ovos (Tabela 7 e Fig. 1).

O processo granulomatoso é entendido como uma tentativa do hospedeiro para controlar a dispersão de substâncias antigênicas e restringi-las ao local de deposição, onde seriam desnaturadas $c$ metabolizadas. A duração c o tamanho do granuloma scriam proporcionais à persistência do ovo na lesão c a capacidade de destruição dos antígenos por parte das células do hospedeiro (Lichtenberg17,18, 1962, 1964).

Domingo c Warren ${ }^{13}$ (1968) verificaram notávcl diminuição da reação granulomatosa, quando a infecção esquistossomótica avançava para a fase crônica. A diminuição do tamanho do granuloma scria uma forma de dessensibilização endógena, rclacionada com a constante e clevada produção de antígenos do ovo. Essa modulação poderia ser benéfica para o hospedeiro, pois os tecidos scriam destruidos $\mathrm{cm}$ menor extensão, a formação de tccido fibroso scria menos intensa, $c$ ainda, os antígenos seriam seqücstrados e destruídos mais rapidamente. Buchanan e col. ${ }^{4}$ (1973) sugeriram quc, cm decorrência da supressão da resposta imunc cclular, uma docnça sistêmica, fatal, porleria estar se desenvolvendo. Numa segunda fase mais adiantada da docnça, os ovos são circundados por uma zona de necrose liquefativa, contendo restos celulares e neutrólilos fragmentados. A contaminação das lesões hepáticas por bactérias promoveria infeç̧ões sistêmicas, toxemia c septicemia. Segundo os mesmos autores, o organismo do hospedeiro, uma vez apresentando incapacidade de montar uma resposta imune mediada por células, torna-se indefeso contra as atividades enzimáticas c fosfolipídicas dos ovos de $S$. mansoni. 
A participação de células $T$ e a caracterização de subpopulaçōes de linfócitos que atuam modulando a resposta imune granulomatosa foram evidenciadas por Chensue \& Boros ${ }^{7}$ (1979) e Chensue e $\mathrm{col}^{8}{ }^{8}$ (1980). A participação de anticorpos com ação de neutralizar os produtos hepatotóxicos do ovo foi sugerido por vários autores (Buchanan e col. ${ }^{4}$ 1973; Boros e col. ${ }^{2}$, 1975; Colley ${ }^{10}, 1975$; Brito e col. ${ }^{3}, 1983$ ).

Não se observou diferença significativa no tamanho dos granulomas das linhagens $\mathrm{BH}$ e $\mathrm{SJ}$ em todas as vísceras estudadas. A infecção dos camundongos com cercárias originadas em moluscos mais susceptiveis determinou diminuição no tamanho dos granulomas em todas as vísceras. Uma modulação mais precoce dos granulomas pode ter ocorrido em decorrência de uma apresentação mais rápida dos antígenos dos ovos responsáveis pcla indução da reação granulomatosa.

Os resultados obtidos são importantes, pois há evidência de maior adaptação no campo das linhagens sulinas ao seu vetor $B$. tenagophila. Com a crescente susceptibilidade de $B$. tenagophila às linhagens autóctones do $S$. mansoni, os portadores vertebrados eliminariam, cada vcz mais, maior número de ovos por grama de fezes, o que facilitaria a dispersão da docnça na região Sul do Brasil.

\section{Conclusøes}

Constatou-se que camundongos expostos ao $S$. mansoni, oriundos de $B$. tenagophila sclecionadas gencticamente para o caráter susceptibilidade, eliminaram maior número de ovos do parasita nas fczes. A maior susceptibilidade de $B$. glabrata c $B$. tenagophila detcrminou maior número de granulomas esquistossomóticos por área de tecido hepático, em rocdores infectados com as cercárias originadas nesses moluscos. Nos mesmos rocdores, verificou-se que o tamanho dos granulomas hepáticos, csplênicos e intestinais, variou inversamente à taxa de infecção dos grupos de moluscos dos quais foram obtidas as cercárias infectantes.

ZANOTTI-MAGALHÃES, E.M. et al. [Relationship between the pathogenicity of Schistoma mansoni in mice and the susceptibility of the vector mollusc. I. Number of eggs in the feces and number and size of granulomas in the visceras]. Rev. Saúde Pública, 27: 412-20, 1993. The influence of the susceptibility of the vector snails of $S$. mansoni on the development of the pathogenicity of the worm to the host was studied. Off-spring of snails Biomphalaria glabrata and Biomphalaria tenagophila were used, selected with regard to the susceptibility to $S$. mansoni of the strains BH and SJ traih, respectively. Paren- teral, $F_{1}, F_{2}, F_{3}$ and $F_{4}$ generation cercariae were used for the infection of $S$ wiss mice, which were killed eight weeks after infection. The number of eggs in the feces and the number of granulomas in the liver, spleen and intestines were counted. The size of the granulomatous reactions was evaluated. The results led to the conclusion that greater susceptibility of $B$. tenagophila was associated with a larger egg production in the feces and a higher density of granulomas in the liver. There is a clear inverse relationship between the area of hepatic, spleenic and intestinal granulomas and the rate of infection of the snails which served as intermediate hosts for the S.mansoni.

Keywords: Schistosoma mansoni, pathogenicity. Biomphalaria, parasitology. Parasite egg count, utilization. Granuloma, parasitology.

\section{Referênclas Bibliográficas}

1. ANDERSON, L.A. \& CHEEVER, A.W. Comparison of geographical strains of Schistosoma mansoni in mouse. Bull. World Healih Organ., 46: 233-42, 1972.

2. BOROS, D.R.; PELLEY, R.P.; WARREN, K.S. Spontaneous modulation of granulomatous hipersensitivity in schistosomiasis mansoni. J. Immunol., 114: 1437-41, 1975.

3. BRITO, T.D.; HOSIIINO-SHIMIZU, S.; SILVA, L.C.; KANAMURA, H.; COSTA, C.M.; PINTO, P.S. Immunopathology of experimental schistosome ( $S$. mansoni) egg granulomas in mice - possible defence mechanisms mediated by local immune complexes. J. Pathol., 140: $17-28,1983$.

4. BUCIANAN, R.D.; FINE, D.P.; COLLEY, D.G. Schistosoma mansoni infection in mice depleted of thymusdependent lymphocytes. II. Pathology and altered pathogenesis. Am. J. Pathol., 71: 207-17, 1973.

5. CHEEVER, A.W. A quantitative post-morten study of schistosomiasis mansoni in man. Am. J. Trop. Med. Hyg., 17: 38-64, 1968.

6. CHEEVER, A.W.; KAMEL, I.A.; ELWI, A.M.; MOSSIMANN, J.E.; DANNER, R. Schistosoma mansoni and Schistosoma haematobium infections in Egypt. II. Quantitative parasitological findings at necropsy. Am.J. Trop.Med.lHyg., 26: 702-16, 1977.

7. CHENSUE, S.W. \& BOROS, D.L. Modulation of granulom atous hipersensitivity. I. Characterization of T lymphocytes involved in the adoptive suppression of granuloma formation in Schistosoma mansoni infected mice. $J$. Immunol., 123: 1409-14, 1979.

8. CHENSUE, S.W.; BOROS, D.L.; DAVID, C.S. Regulation of granulomatous inflamation in murine schistosomiasis: in vitro characterization of $\mathrm{T}$ lymphocytes subsets involved in the production and suppression of migration inhibition factor. J. Exp. Med., 15I: 1398-412, 1980.

9. COELIIO, M.V. Suscetibilidade de Australorbis tenagophilus à infecção por Schistosoma mansoni. Rev. Inst. Med. Trop. São Paulo, 4: 289-95, 1962.

10. COLLEY, D.G. Immune responses to a soluble schistosomal egg antigen preparation during chronic primary in. fection with Schistosoma mansoni. J. Immunol., 115: $150-6,1975$.

11. DIAS, L.C.S.; GLASSER, C.M.; ETZEL, A.; KAWAZOE, U.; IIOSHINO-SHILMIZU, S.; KANAMURA, II.Y.; CORDEIRO, J.A.; MARÇALJJR., O; CARVALHO, J.F.; PATUCCI, R. The epidemiology and control of schistosomiasis mansoni where Biomphalaria tenagophila is the snail host. Rev. Saúde Pública, 22:462-3,1988. 
12. DOENHOFF, MJ.; HASSOUNAH, O.; MURARE, H.; BAIN, J.; LUCAS, S. The schistosome egg granuloma: immunopathology in the cause of host protection or parasite survival? Trans. R. Soc. Trop. Med. Hyg., 80: 503$14,1986$.

13. DOMINGO, E.O. \& WARREN, K.S. Endogenous desensibilization: changing host granulomatous response to schistosome eggs at different stages of infection with Schistosoma mansoni. Am. J. Pathol., 52: 369-79, 1968.

14. GUARALDO, A.M.A.; MAGALHÄES, L.A.; RANGEL, H.A.; PAREJA, G. Evolução dos esporocistos de Schistosoma mansoni Sambon, 1907, em Biomphalaria glabrata (Say, 1818) e Biomphalaria tenagophila (D'Orbigny, 1835). Rev. Saúde Pública, 15: 436-48, 1981.

15. KASSIM, O.O.; CHEEVER, A.W; RICIIARDS, C.S. Schistosoma mansoni: mice infected with different worm strains. Exp. Parasitol., 48: 220-4, 1979.

16. KOMYIA, Y. \& KOBAYASHI, A. Evaluation of Kato's thick smear technic with a cellophane cover for helminth eggs in feces. Jpn. J. Med. Sci. Biol., 19: 59-64, 1966.

17. LICHITENBERG, F.V. Host response to eggs of Schistoso. ma mansoni. I. Granuloma formation in the insensitized laboratory mouse. An. J. Pathol., 41: 711-31, 1962.

18. LICIITENBERG, F.V. Studies on granuloma formation. III. Antigen sequestration and destruction in the schistosome pseudotubercle. Am. J. Pathol., 45: 75-93, 1964

19. LIMA, J.N. Estudo clínico e terapêutico da esquistossomose mansônica $\mathrm{cm}$ menores de 15 anos do Vale do Ribcira, SP: comparação de oxamniquine, prazinquantel e associação dessas drogas em baixas doses. Campinas, 1991. [Dissertação de Mestrado - Instituto de Biologia UNICAMP]

20. MAGALHĀES, LA. Técnica para avaliação da viabilidade de penetração de cercárias de Schistosoma mansoni em Mus musculus. Hospital, 75: 137-40, 1969.

21. MAGALHĀES, L.A.; ALCÂNTARA, F.G.; CARVALIIO, J.F. Alguns dados referentes ao estudo parasitológico e anatomapatológico de duas linhagens de Schistosoma mansoni, Sambon, 1907. Rev. Saúde Pública, 9: 1-5, 1975.

22. MAGALIIX̉ES, LA.; ALCÂNTARA, F.G.; CARVALHO, J.F. Distribuição de lesões esquistossomóticas extra. hepáticas em camundongos infectados pelas linhagens BIl e SJ de Schistosoma mansoni. Rev. Saúde Pública, 13: 326-34, 1979.

23. NEWTON, W.L. The comparative tissue reaction of two strains of Australorbis glabratus to infection with Schistosoma mansoni. J. Parasitol., 38: 362-6, 1952.

24. NEWTON, W.L. The inheritance of suscetibility to infection with Schistosoma mansoni in Australorbis glabra. lus. Exp. Parasitol., 2: 242-57, 1953.
25. PARAENSE, W.L. \& CÔRREA, L.R. Variation in susceptibility of population of Australorbis glabratus to a strain of Schistosoma mansoni. Rev. Inst. Med. Trop. Säo Paulo, 5: 15-22, 1963.

26. PARAENSE, W.L. \& CÓRREA, L.R. Susceptibility of Australorbis tenagophilus to infection with Schistoso. ma mansoni. Rev. Inst. Med. Trop. São Paulo, 5: 23-9, 1963.

27. PARAENSE, W.L. \& CÔRREA, L.R. Differential susceptibility of Biomphalaria tenagophila populations to infection with a strain of Schistosoma mansoni.J. Parasitol., 64: 822-6, 1978.

28. PELLEGRINO, J. \& BRENER, Z. Method for isolating Schistosoma mansoni granulomas from mouse liver. $J$. Parasitol., 42: 564, 1956.

29. POWERS, K.G. \& CHEEVER, A.W. Comparison of geographical strains of Schistosoma mansoni in thesus monkey. Bull. World Heallh Organ., 46: 295-300, 1972.

30. RICHARDS, C.S. Genetic of a molluscan vector of schistosomiasis. Nature, 227: 806-10, 1970.

31. RICHARDS, C.S. \& MERRITT, J.W. Genetic factors in the susceptibility of juvenile Biomphalaria glabrata to Schistosoma mansoni infection. Am. J. Trop. Med. Ilyg, 21: 425-34, 1972.

32. RICIIARDS, C.S. Schistosoma mansoni: susceptibility reversal with age in the snail host Biomphalaria glabrata. Exp. Parasitol., 42: 165-8, 1977.

33. SANTOS, N.R. Esquistossomose mansônica autóctone no Vale do Médio Paraíba, Estado de São Paulo, Brasil: contribuição para o estudo da zona endêmica, São Paulo, 1967. [Tese de Doutorado - Faculdade de Medicina da USP].

34. SANTANA, J.V.; MAGALHÃES, L.A.; RANGEL, H.A. Scleção de linhagem de Biomphaloria glabrata e $B$ iomphalaria lenogophila visando maior susceptibilidade ao Schistosoma mansoni. Rev. Saúde Pública, 12: 67.77, 1978.

35. SAOUD, M.F.A. The infectivity and pathogenicity of geographical strains of Schistasoma mansoni. Trans. $R$. Soc.Trop. Med. Ilyg., 60: 585-600, 1966.

36. YOLLES, T.K.; MOORE, P.V.; DEGINSTI, D.L.; RIPSON, C.A.; MELENEY, H.E. A technique for the perfusion of laboratory animals for the recovery of schistosomes. J. Parasilol., 33: 419-26, 1947.

37. ZANOTTI-MAGALHÄES, E.M.; MAGALHĀES, L.A.; CARVALIIO, J.F. Relação entre patogenicidade do $S$ chislosoma mansoni $\mathrm{em}$ camundongos e a susceptibilidade do molusco vetor. I. Infectividade da cercária e carga parasitária. Rev. Saúde Pública, 25: 359-66, 1991.

Recebido para publicação em 25.3.1993

Reapresentado em 8.9.1993

Aprovado para publicação em 20.9.1993 